and C-band internally-matched quasi-MMIC power GaN devices, In: Proceedings of the $42^{\text {nd }}$ European Microwave Conference (EuMC), 2012, pp. 1023-1026.

5. C. Berrached, D. Bouw, M. Camiade, and D. Barataud, Wideband High Efficiency High Power GaN Amplifiers Using MIC and QuasiMMIC Technologies, In: Proceedings of Microwave Integrated Circuits Conference (EuMIC), 2013, pp. 424-427.

6. S. An, D. Kim, J. Yook, S. Kim, W. Lee, J. Kim, and J. Yook, An $\mathrm{X}$-band RLC matched power amplifier using quasi-MMIC technology, Microw Opt Technol Lett 57 (2015), 2803-2807.

7. K. Chen and D. Peroulis, A. 31-GHz class-F power amplifier with $82 \%$ power-added-efficiency, IEEE Microw Wireless Compon Lett 23 (2013), 436-438

(C) 2016 Wiley Periodicals, Inc.

\section{MULTI-BAND CPW FED MIMO ANTENNA FOR BLUETOOTH, WLAN, AND WIMAX APPLICATIONS}

Irem Desde, Goksenin Bozdag, and Alp Kustepeli

The Department of Electrical and Electronics Engineering, Izmir Institute of Technology, Izmir 35430, Turkey; Corresponding author: gokseninbozdag@iyte.edu.tr

Received 9 February 2016

ABSTRACT: In this letter, multi-band coplanar waveguide (CPW) fed multiple-input-multiple-output (MIMO) antenna is presented for Bluetooth, WLAN and WiMAX applications. The elements of MIMO antenna are identical $C P W$-fed printed monopole antennas whose bandwidth performances are improved by employing inverse $U$ and meander line slots. In the design of the antennas, a low-cost FR4 substrate is used and the size of the element antennas are optimized as $35 \mathrm{~mm} \times 30 \mathrm{~mm}$. According to the measurements, $S_{11}$ is below $-10 \mathrm{~dB}$ in $2.38 \mathrm{GHz}-2.52 \mathrm{GHz}$ and $3.19 \mathrm{GHz}-6.44 \mathrm{GHz}$ bands with $0.2 \mathrm{~dB}$ and $2.9 \mathrm{~dB}$ average peak realized gains, respectively. The element antennas are placed orthogonally and fed independently to obtain MIMO structure whose size is optimized as $42 \mathrm{~mm} \times 62 \mathrm{~mm}$. The performance of MIMO antenna is also examined in terms of diversity parameters such as envelope correlation coefficient and apparent diversity gain, which are lower than 0.02 and higher than 9.9 in the operating bands, respectively. (C) 2016 Wiley Periodicals, Inc. Microwave Opt Technol Lett 58:2182-2186, 2016; View this article online at wileyonlinelibrary.com. DOI 10.1002/ mop.30001

Key words: multi-band antenna; multiple-input-multiple-output antenna; envelope correlation coefficient; apparent diversity gain

\section{INTRODUCTION}

Multiple-input-multiple-output (MIMO) systems have been employed widely in modern wireless communication in the last decades because they increase channel capacity, channel reliability and data rate by reducing multipath fading without the need of additional transmitted power and bandwidth [1-3]. Antenna diversity is one of the well-known techniques used in MIMO systems and it is used to obtain independent replicas of the original signal to avoid channel attenuation such as deep fades. There are several methods to produce diversity. Among them spatial, pattern and polarization diversities are the ones mostly employed. In spatial diversity, the antennas are separated in space for multipath arrival. In pattern diversity, multiple directional beams are employed to take the advantage of incoherence of the rays with different angle of arrivals [2,3]. Polarization diversity uses antennas with different polarizations and it is effective as spatial diversity, providing space and cost saving
TABLE 1 Frequency Allocations

\begin{tabular}{lll}
\hline Band Designation & \multicolumn{2}{c}{ Frequency $\left(\mathrm{GH}_{\mathrm{Z}}\right)$} \\
\hline Bluetooth & $2.400-2.485$ & $(802.15 .1)$ \\
Wireless local area & $2.412-2.472$ & $(802.11 / \mathrm{a}-\mathrm{n})$ \\
network (WLAN) & $3.657-3.690$ & $(802.11 \mathrm{y})$ \\
& $4.942-4.948$ & $(802.11 / \mathrm{a}-\mathrm{j})$ \\
WiMAX & $5.180-5.825$ & $(802.11 / \mathrm{a}-\mathrm{n})$ \\
& $2.4,5.8$ & (Unlicensed) \\
& $2.5,3.5$ & (Licensed) \\
\hline
\end{tabular}

and compensating polarization mismatches $[2,4]$. Although theoretical capacity of MIMO systems linearly increases with the number of antenna elements in a rich multipath environment, it is reduced because of the correlation between element antennas in practice [5]. This correlation also deteriorates the desired radiation pattern by increasing the mutual effects. Therefore, MIMO antennas must have low envelope correlation coefficient $\left(\rho_{\mathrm{e}}\right)$, high diversity gain and high isolation.

Moreover, MIMO antennas need to be compact, lightweighted, relatively small and planar in today's space and weight limited devices. Many modern communication systems such as Bluetooth, WLAN and WiMAX are allocated in multiple frequency bands as can be seen in Table 1. Hence, MIMO antennas designed for those systems need to be multi-band or wideband. Printed antennas are preferable for those purposes because of their convenience, easy fabrication and integration in the applications [6-8]. Many printed MIMO antennas have been proposed for Bluetooth/WLAN/WiMAX applications in the literature [7-9]. The MIMO antenna in Ref. 7 only covers $5.8 \mathrm{GHz}$ band and the one in [8] only covers $2.45 \mathrm{GHz}$ band. It is also seen that the bandwidth requirement in Refs. [8] and [9] is determined as $\left|S_{11}\right|<-6 \mathrm{~dB}$, which is actually a high value. Therefore, their bandwidth performances need to be improved for their effective usage.

In regard to feeding of an antenna, coplanar waveguide (CPW) feeding attracts more and more attention lately due to its advantages over microstrip feeding. It has wider bandwidth performance with lower dispersion and lower radiation leakage than microstrip feed line. Furthermore, its implementation to active and passive devices is easier. The detailed information about CPWs can be found in [10]. Even though there are some studies about CPW-fed MIMO antennas in the literature [11,12], they do not cover all the bands given in Table 1. Therefore, in this letter, multi-band CPW-fed MIMO antenna for Bluetooth, WLAN and WiMAX applications is investigated.

\section{ELEMENT ANTENNA DESIGN AND RESULTS}

To obtain the MIMO antenna, first of all, a wideband element antenna covering most of the WLAN bands around $5 \mathrm{GHz}$ was intended to design by using a rectangular patch with the dimensions of $14 \mathrm{~mm} \times 16 \mathrm{~mm}$ as seen in Figure 1. In the preliminary analysis for the comparison of feeding structures, microstrip feeding lines including the ones having inset-fed, partial ground and also grounded CPWs were investigated as well, and it was seen that the optimum results were obtained with CPW feeding in terms of impedance matching and gain, as expected. Comprehensive numerical studies are performed by using HFSS to obtain the optimum design before the fabrications and measurements.

Implementation of proper slots having specific locations on printed antennas is generally used for the excitation of additional operating frequencies [12,13], band stopping [11,14], 


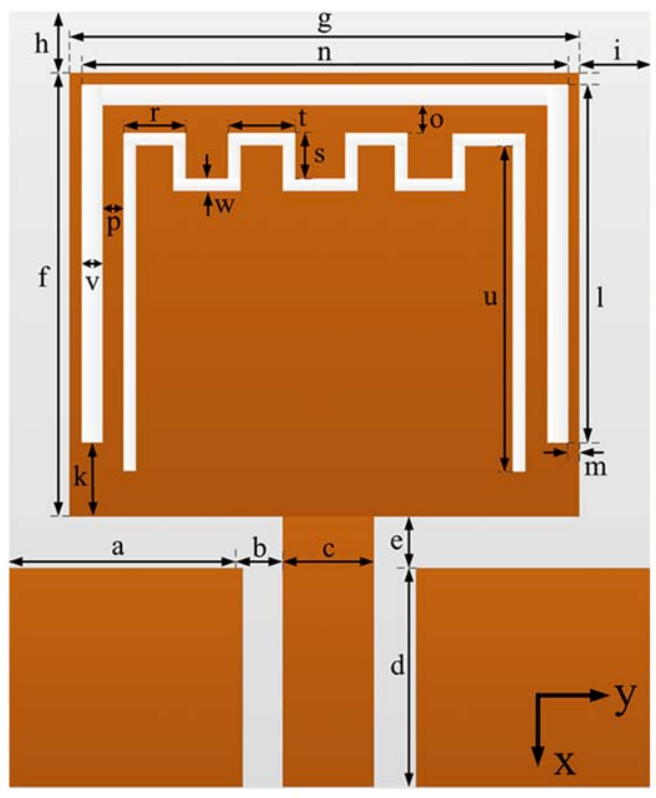

(a)

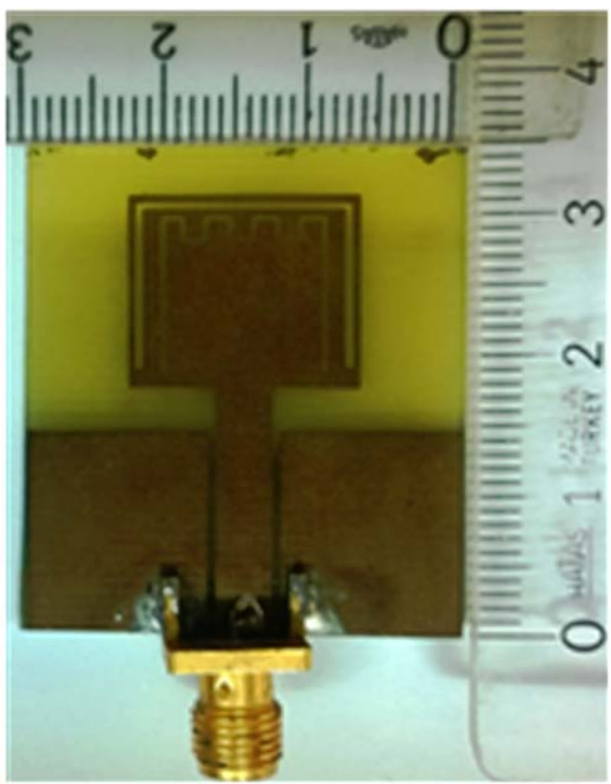

(b)

Figure 1 Element antenna (a) Geometry (b) Fabricated. [Color figure can be viewed in the online issue, which is available at wileyonlinelibrary.com.]

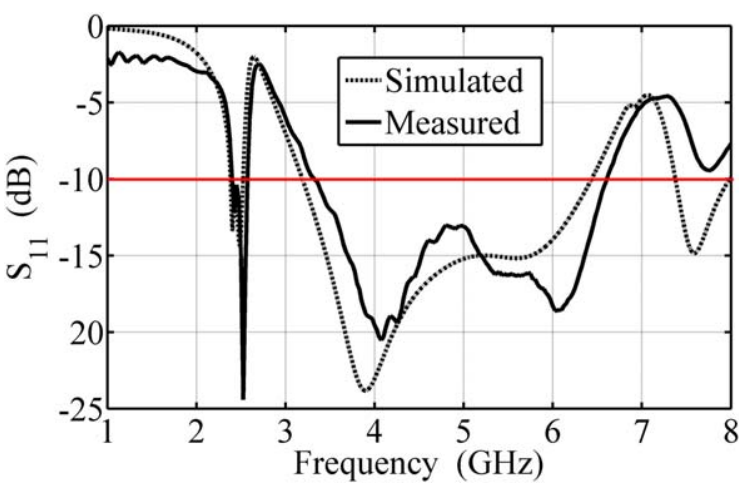

Figure 2 S11 of the element antenna. [Color figure can be viewed in the online issue, which is available at wileyonlinelibrary.com.]

antenna miniaturization [15], gain and bandwidth enhancements [16]. In this study, slot loading technique was employed to cover the $2.4 \mathrm{GHz}-2.5 \mathrm{GHz}$ band by implementing an inverse symmetric $U$ slot on the radiating patch. The length and the width of the slot were used to control the excitation frequency and bandwidth of the lower band, respectively. However, the

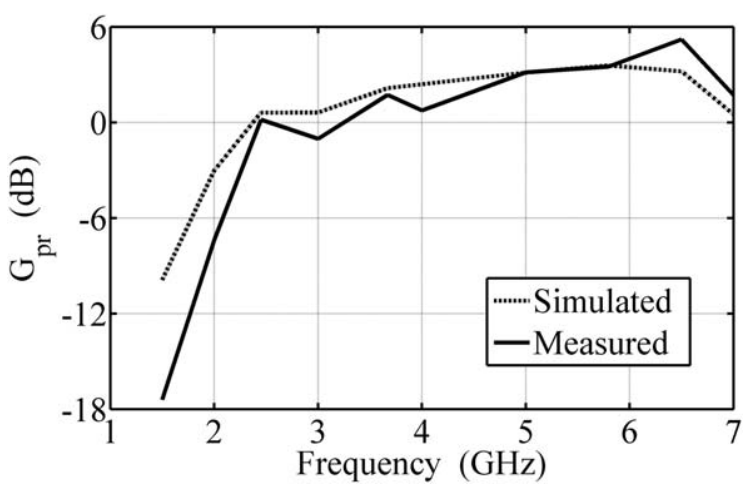

Figure 3 Peak realized gain of the element antenna maximum bandwidth had been obtained as $60 \mathrm{MHz}$ which is not sufficient for Bluetooth applications and a meander line slot was employed in addition to the first one to obtain the necessary bandwidth. The antenna was fabricated by using a low-cost FR4 substrate whose effective permittivity, loss tangent and thickness are $4.4,0.02$ and $1.5 \mathrm{~mm}$, respectively. Illustration of the resulting antenna with all necessary dimensions and the fabricated one are presented in Figures 1(a) and 1(b), respectively.

The effect of combining the bandwidths of the two slots in increasing the total bandwidth around $2.45 \mathrm{GHz}$ can be seen in both of the simulated and measured results presented in Figure 2. Simulated and measured and peak realized gains $\left(\mathrm{G}_{\mathrm{pr}}\right)$ are presented in Figure 3. According to the figures, simulated and measured values are in very good agreement and the antenna operates between $2.38 \mathrm{GHz}-2.52 \mathrm{GHz}$ and $3.19 \mathrm{GHz}-$ $6.44 \mathrm{GHz}$ with average peak realized gains of $0.2 \mathrm{~dB}$ and 2.9 $\mathrm{dB}$, respectively. Therefore, the element antenna can be used for Bluetooth, WLAN and WiMAX applications.

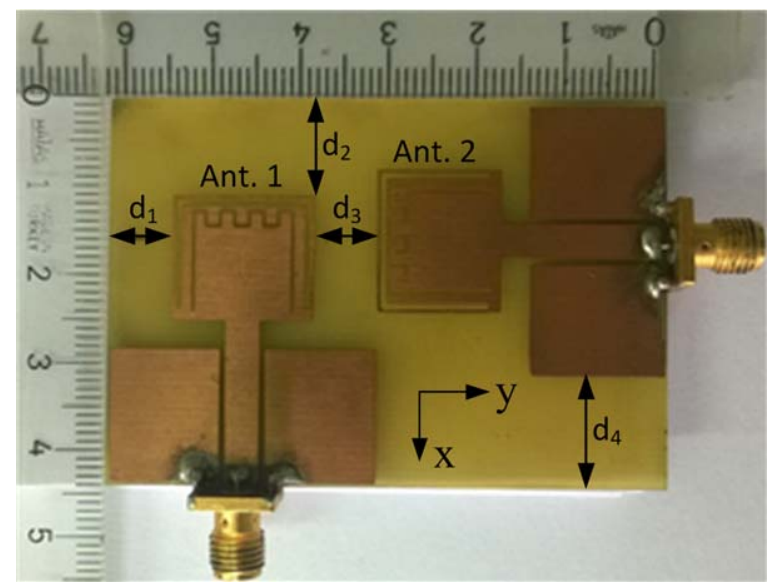

Figure 4 Structure of MIMO antenna (a) Geometry (b) Fabricated (d1, $3=7, \mathrm{~d} 2=10, \mathrm{~d} 4=12$ all dimensions are in $\mathrm{mm}$ ). [Color figure can be viewed in the online issue, which is available at wileyonlinelibrary.com.] 


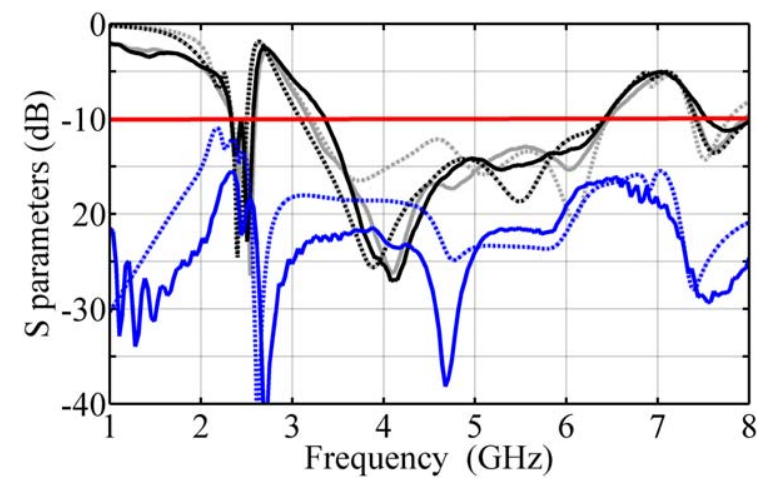

Figure $5 \mathrm{~S}$ parameters of MIMO antenna (Dotted: Simulated, Solid: Measured; Black: S11, Gray: S22, Blue: S21). [Color figure can be viewed in the online issue, which is available at wileyonlinelibrary.com.]

\section{MIMO ANTENNA DESIGN AND RESULTS}

CPW-fed MIMO antenna was designed by using two element antennas and they were placed orthogonally in order to utilize the polarization diversity and reduce the mutual coupling between them $[4,11]$. The distance between the element antennas was optimized to avoid bandwidth deteriorations by considering compactness. The dimensions of the resulting MIMO antenna were optimized as $42 \mathrm{~mm} \times 62 \mathrm{~mm}$ and it is shown in Figure 4. These dimensions make the MIMO antenna more compact when it is compared with the other antennas proposed in Refs. [9] and [13].

The simulated and measured $S_{11}, S_{22}$ and $S_{21}$ parameters of the MIMO antenna are shown in Figure 5. It is seen that both $S_{11}$ and $S_{22}$ parameters are below $-10 \mathrm{~dB}$ in $2.38 \mathrm{GHz}-2.52 \mathrm{GHz}$ and 3.19 $\mathrm{GHz}-6.44 \mathrm{GHz}$ bands corresponding to Bluetooth, WLAN and
WiMAX. The results are consistent and in a very good agreement with the ones obtained in the previous section. High isolation between antenna elements in a MIMO system is required to reduce mutual coupling effects and increase MIMO capacity. Therefore, $\mathrm{S}_{21}$ parameter which indicates the isolation between the antennas, was examined and the results are also presented in Figure 5. According to the figure, the isolation is always greater than $15 \mathrm{~dB}$ in the interested frequency range. Those results can be considered very satisfactory especially when compared with the $10 \mathrm{~dB}$ level accepted to be enough [1]. Thus, it can be said that the mutual coupling of the element antennas is low and they can operate independently from each other. In Figure 6, simulated surface current distributions of the proposed antenna are presented for $2.45 \mathrm{GHz}$ and 5.8 GHz. Current distributions shown in Figures 6(a) and 6(b) are obtained when port 1 is excited, and those shown in Figures 6(c) and $6(\mathrm{~d})$ are obtained when port 2 is excited. According to the figure, current is concentrated around the slot loadings for $2.45 \mathrm{GHz}$. For $5.8 \mathrm{GHz}$, it is concentrated at the corners of radiating patch and ground. It can also be observed from the figure that the coupling between the element antennas at $2.45 \mathrm{GHz}$ is higher than the one at $5.8 \mathrm{GHz}$ but its value is less than $-15 \mathrm{~dB}$ which was obtained by optimizing $d_{3}$ and $d_{4}$.

The simulated and measured normalized co- and crosspolarization patterns are presented for $2.45 \mathrm{GHz}$ and $5.8 \mathrm{GHz}$ in Figure 7. In the measurements, when one of the antennas is excited, the other one is terminated with a matched load. One can see from Figure 7 that each antenna in MIMO structure has almost omni-directional radiation patterns in its azimuth plane $(y-z$ plane for Antenna 1 and $x$ $z$ plane for Antenna 2). In the normalized co-polarization radiation patterns, it is observed that there are no sharp nulls which are not desired for mobile communication [9]. Co- and cross-polarization discrimination levels are also better than $10 \mathrm{~dB}$ at those frequencies.
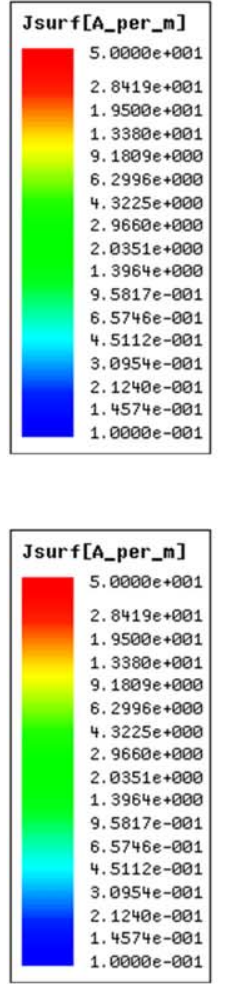

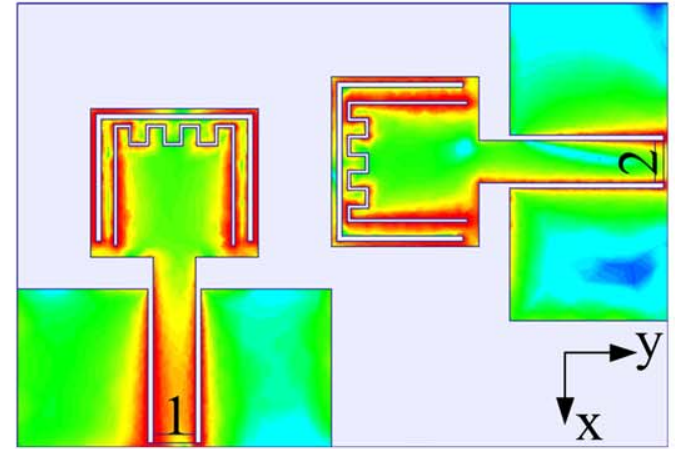

(a)

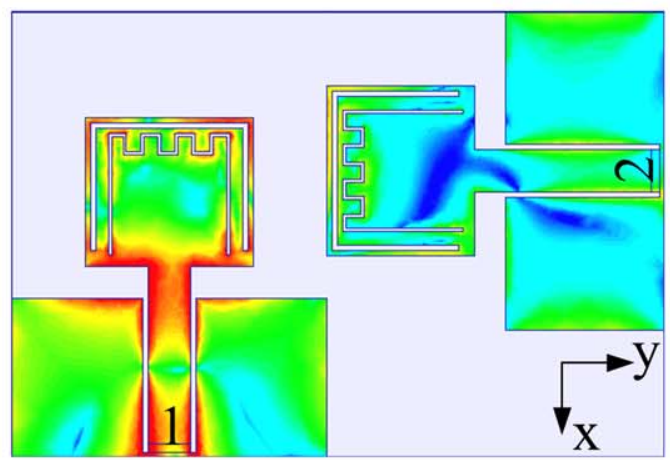

(c)

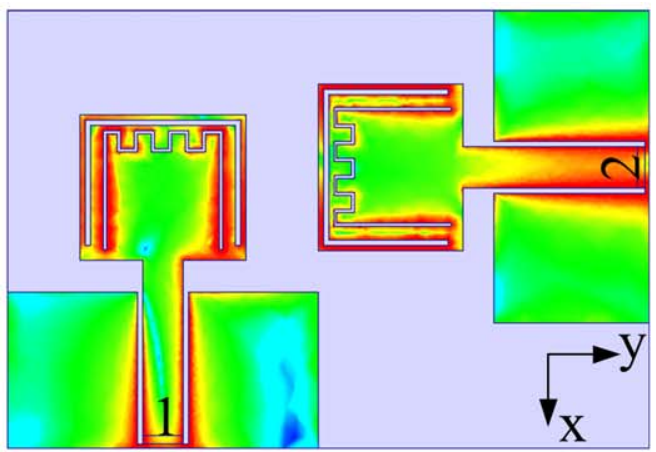

(b)

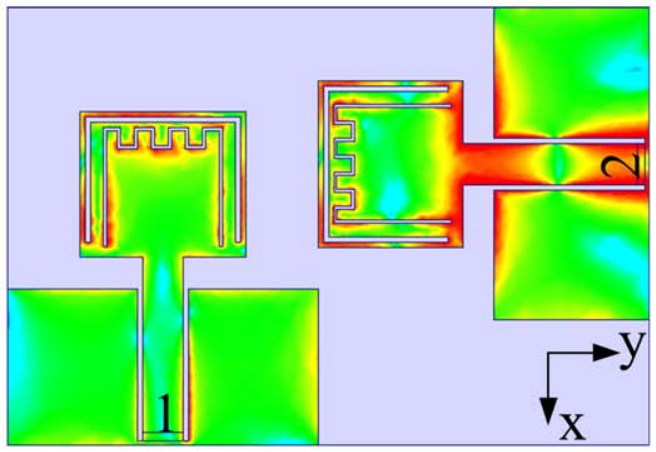

(d)

Figure 6 Simulated surface current distributions (a) Port 1 is excited at $2.45 \mathrm{GHz}$ (b) Port 1 is excited at $5.8 \mathrm{GHz}$, (c) Port 2 is excited at $2.45 \mathrm{GHz}$, (d) Port 2 is excited at $5.8 \mathrm{GHz}$. [Color figure can be viewed in the online issue, which is available at wileyonlinelibrary.com.] 

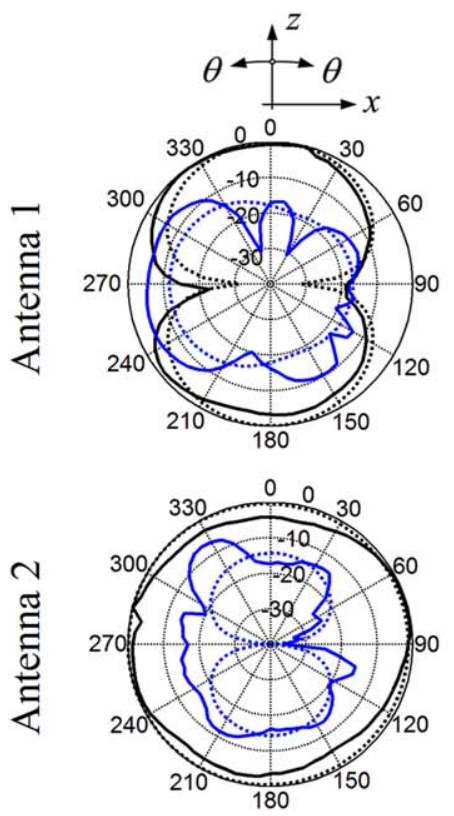

$2.45 \mathrm{GHz}$
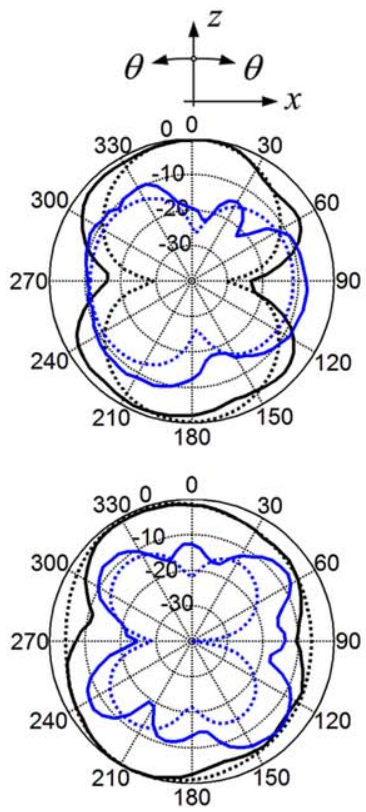

$5.8 \mathrm{GHz}$
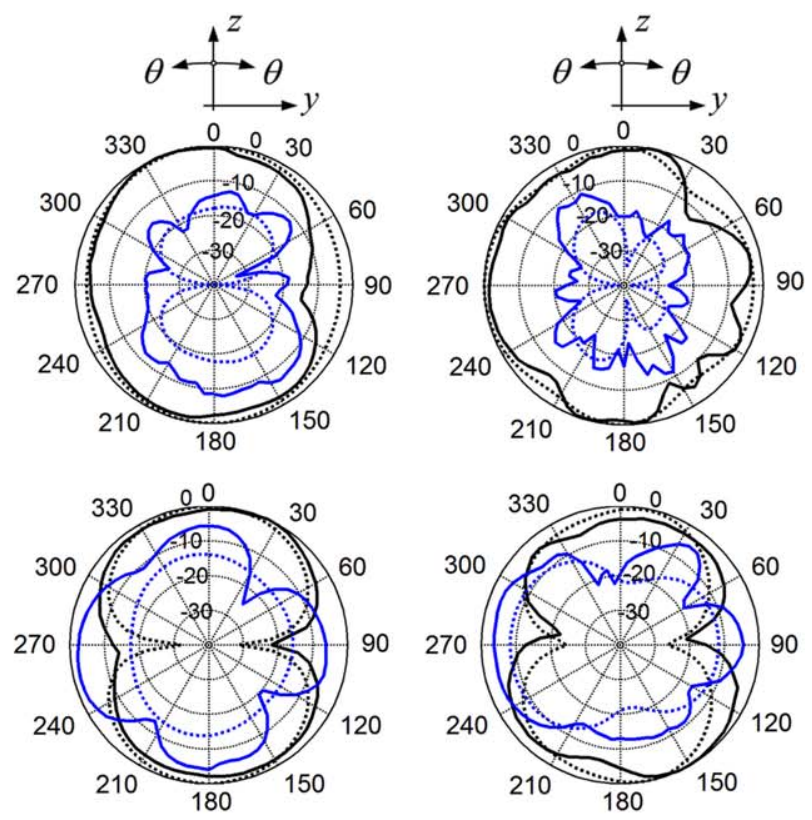

$2.45 \mathrm{GHz}$

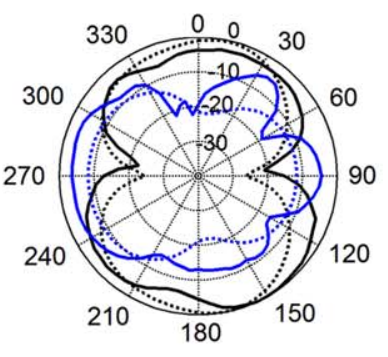

$5.8 \mathrm{GHz}$

Figure 7 Normalized radiations patterns of the MIMO antenna (Black: Measured Co-Pol, Black Dashed: Simulated Co-Pol, Blue: Measured CrossPol, Blue Dashed: Simulated Cross-Pol). [Color figure can be viewed in the online issue, which is available at wileyonlinelibrary.com.]

Envelope correlation coefficient $\rho_{\mathrm{e}}$ is an important figure of merit which is used to evaluate the overall diversity performance of MIMO antennas. It can be determined by many approaches such as full sphere complex radiation pattern, impedance matrix, Clarke's formula and S parameters [5,8,17-20]. Among those, the quicker approach based on S parameters as in Ref. [20] is not only less laborious and simpler but also suitable for the determination of measured $\rho_{\mathrm{e}}$ which is given by

$$
\rho_{e}=\frac{\left|S_{11}^{*} S_{12}+S_{21}^{*} S_{22}\right|^{2}}{\left(1-\left(\left|S_{11}\right|^{2}+\left|S_{21}\right|^{2}\right)\right)\left(1-\left(\left|S_{22}\right|^{2}+\left|S_{12}\right|^{2}\right)\right)}
$$

The simulated and measured values of the MIMO antenna are presented in Figure 8. In the interested frequency range, the measured values of $\rho_{\mathrm{e}}$ is below 0.02 leading to good diversity performance. Diversity gain $G_{\mathrm{div}}$ indicates the improvement in SNR of a received signal that is obtained from different receiver antennas also called branches $[4,21] . G_{d i v}=P_{d i v} / P_{\text {branch }}$, where $P_{\text {div }}$ is the power level after diversity combining and $P_{\text {branch }}$ is the power level of the reference branch, permits a direct comparison of improvement provided by MIMO structure compared to a single antenna [4]. $G_{\text {div }}$ is called apparent diversity gain $G_{\text {app }}$ when the reference branch is chosen as the stronger of the two branches and it is defined as $G_{a p p}$

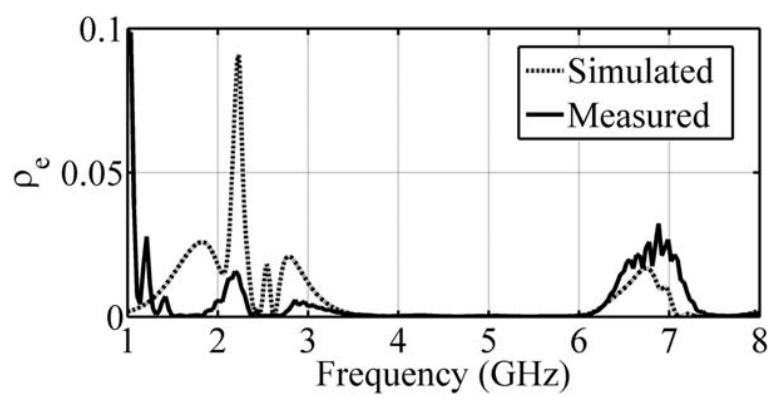

Figure 8 Envelope correlation coefficient of the MIMO antenna
$=10 \sqrt{1-\left|\rho_{e}\right|^{2}}$ [21]. Figure 9 shows the simulated and measured $G_{\text {app }}$. According to the figure, $G_{\text {app }}$ is higher than 9.9 in the interested bands, which provides a very good diversity performance for practical multipath environments.

\section{CONCLUSION}

A slot loaded CPW-fed printed monopole antenna has been designed and used as the element antenna to obtain a multi-band CPW-fed MIMO antenna. The element antenna operates in 2.38 $\mathrm{GHz}-2.52 \mathrm{GHz}$ and $3.19 \mathrm{GHz}-6.44 \mathrm{GHz}$ bands with average peak realized gains of $0.2 \mathrm{~dB}$ and $2.9 \mathrm{~dB}$, respectively, and it is suitable for Bluetooth, WLAN and WiMAX applications. The important performance parameters such as isolation between antenna elements, envelope correlation coefficient $\rho_{\mathrm{e}}$ and apparent diversity gain $G_{\text {app }}$ were analyzed to investigate the diversity performance of the proposed MIMO antenna. From the measurements, it is seen that the antenna provides isolation greater than $15 \mathrm{~dB}, \rho_{\mathrm{e}}$ lower than 0.02 and $G_{\text {app }}$ higher than $9.9 \mathrm{~dB}$ in the interested frequency range. There is a good agreement between the simulated and measured results. Therefore, the proposed MIMO antenna is suitable for integration and usage within portable devices.

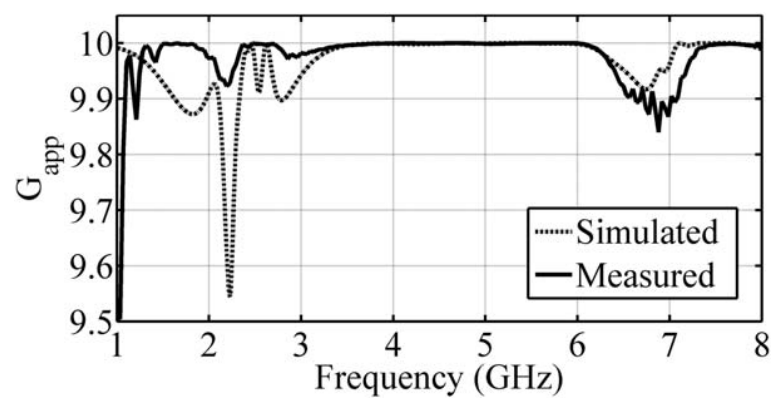

Figure 9 Apparent diversity gain of the MIMO antenna. 


\section{REFERENCES}

1. M.P. Karaboikis, V.C. Papamichael, G.F. Tsachtsiris, C.F. Soras, and V.T. Makios, Integrating compact printed antennas onto small diversity/MIMO terminals, IEEE Trans Antennas Propag 56 (2008), 2067-2078.

2. J. Oh and K. Sarabandi, Compact, low profile, common aperture polarization, and pattern diversity antennas, IEEE Trans Antenna Propag 62 (2014), 569-576.

3. L. Sun, W. Huang, B. Sun, Q. Sun, and J. Fan, Two-port pattern diversity antenna for $3 \mathrm{G}$ and $4 \mathrm{G}$ MIMO indoor applications, IEEE Antenna Wireless Propag Lett 13 (2014), 1573-1576.

4. C.B. Dietrich, K. Dietze, J.R. Nealy, and W.L. Stutzman, Spatial, polarization, and pattern diversity for wireless handheld terminals, IEEE Trans Antenna Propag 49 (2001), 1271-1281.

5. J. Thaysen and K. B. Jakobsen, Envelope correlation in (N, N) MIMO antenna array from scattering parameters, Microw Opt Tech Lett 48 (2006), 832-834.

6. P. S. Bakariya, S. Dwari, M. Sarkar, and M.K. Mandal, Proximitycoupled microstrip antenna for bluetooth, WiMAX and WLAN applications, IEEE Antenna Wireless Propag Lett 14 (2015), 755758.

7. J. Malik, A. Patnaik, and M.V. Kartikeyan, Novel printed MIMO antenna with pattern and polarization diversity, IEEE Antenna Wireless Propag Lett 14 (2015), 739-742.

8. A. Diallo, C. Luxey, P.L. Tuch, R. Staraj, and G. Kossiavas, Enhanced two-antenna structures for universal mobile telecommunications system diversity terminals, IET Microw Antenna Propag 2 (2008), 93-101.

9. M. Sonkki, E.A. Daviu, M.C. Fabres, M.F. Bataller, and E.T Salonen, Improved planar wideband antenna element and its usage in a mobile MIMO system, IEEE Antenna Wireless Propag Lett 11 (2012), 826-829.

10. R.N. Simons, Coplanar Waveguide Circuits, Components, and Systems, Wiley-IEEE Press, NY, 2001.

11. S. Tripathi, A. Mohan, and S. Yadav, A compact octagonal fractal UWB MIMO antenna with WLAN band-rejection, Microwave Opt Tech Lett 57 (2015), 1919-1925.

12. N. Qjaroudi and N. Ghadimi, Design of CPW-fed slot antenna for MIMO system applications, Microw Opt Tech Lett 56 (2014), 12781281.

13. R.Z. Wu, P. Wang, Q. Zheng, and R.P. Li, Compact CPW-fed triple-band antenna for diversity applications, Elect Lett 51 (2015), $735-736$.

14. S. Bakariya, S. Dwari, and M. Sarkar, Triple band notch UWB printed monopole antenna with enhanced bandwidth, Int J Electron Commun 69 (2015), 26-30.

15. S.I. Latif, L. Shafai, and S.K. Sharma, Bandwidth enhancement and size reduction of microstrip slot antennas, IEEE Trans Antenna Propag 53 (2005), 994-1003.

16. K.P. Ray and S.S. Thakur, Ultra wide band vertex truncated printed pentagon monopole antenna, Microw Opt Tech Lett 56 (2014), $2228-2234$.

17. A. Derneryd and G. Kristensson, Signal correlation including antenna coupling, Elect Lett 40 (2004), 157-159.

18. Y.A.S. Dama, R.A. Abd-Alhameed, S.M.R. Jones, D. Zhou, N.J. McEwan, M.B. Child, and P.S. Excell, An envelope correlation formula for (N, N) MIMO antenna arrays using input scattering parameters, and including power losses, Int J Antenna Propag 2011 (2011).

19. R.H. Clarke, A statistical theory of mobile-radio reception. The Bell Sys Tech J 47 (1968), 957-1000.

20. S. Blanch, J. Romeu, and I. Corbella, Exact presentation of antenna system diversity performance from input parameter description, Elect Lett 39 (2003), 705-707.

21. K. Rosengren and P.S. Kildal, Radiation efficiency, correlation, diversity gain and capacity of a six-monopole antenna array for a MIMO system theory, simulation and measurement in reverberation chamber, IEE Proc Microw Antenna Propag 152 (2005), 7-16.

(C) 2016 Wiley Periodicals, Inc.

\section{EXPERIMENTAL VALIDATION OF A WIRELESS SYSTEM FOR THE IRRIGATION MANAGEMENT IN SMART FARMING APPLICATIONS}

\section{Federico Viani}

Department of Information Engineering and Computer Science, ELEDIA Research Center, University of Trento, via Sommarive 9, Trento I-38123, Italy; Corresponding author: federico.viani@unitn.it

Received 9 February 2016

\begin{abstract}
This work is aimed at presenting the water saving potentialities of a scalable smart irrigation system applied to precision agriculture. A fuzzy logic strategy is integrated in a distributed monitoring system based on the wireless sensor network technology. The optimal irrigation schedule is adaptively estimated according to the real-time measurement of the soil status and the weather conditions. The objective of the system is to optimize the water content in the soil to (i) maximize the health status of the plants, (ii) improve the quality of the products, and (iii) reduce the waste of water. The proposed system has been prototyped and experimentally validated in an apple orchard, close to the city of Trento, in the north of Italy. The performances of the proposed system are compared with those of a standard irrigation scheduler to point out the amount of saved water as well as the improved stability of the soil moisture level. (C) 2016 Wiley Periodicals, Inc. Microwave Opt Technol Lett 58:2186-2189, 2016; View this article online at wileyonlinelibrary.com. DOI 10.1002/mop.30000
\end{abstract}

Key words: wireless sensor networks; fuzzy logic; smart farming; decision support system

\section{INTRODUCTION}

The irrigation in agriculture considerably impacts on the global water consumption (up to $80-90 \%$ in the developed countries), and the water withdrawal is expected to increase by $20 \%$ before 2050 [1]. A more efficient exploitation of water resources is mandatory to guarantee the sustainable food production for the fast growing world population [2].

The information and communication technologies have been recognized as fundamental tools to support the technological advancements in the management of the agricultural processes. In this framework, the wireless sensor network $(W S N)$ technology [3] has been applied to enable the distributed monitoring of different physical parameters. The WSN properties such as the scalability, low-cost, self-configurability, and multi-sensing have stimulated the diffusion of small and low-power wireless sensors to implement the so-called "precision agriculture" [4-6]. However, even if the sensing technologies and their integration in embedded wireless devices are available in the state-of-the-art (also commercial products exist nowadays), advanced methodologies for the sensor data processing and for the adaptive control of the irrigation systems have been less investigated. To the best of the author's knowledge, the actuation strategies are limited to preliminary studies or to proprietary and customized management software, often calibrated for specific irrigation modalities and equipment. The dissemination of research results as well as their critical analysis and comparison with the performance of standard irrigation methods is only partially documented.

In this paper, an actuation strategy based on the fuzzy logic [7] for the unsupervised estimation of the optimal irrigation schedule is proposed. The heuristically defined rules have been defined starting from the empirical knowledge of expert farmers in order to adaptively apply the human experience to the time- 